\title{
Fatal paraphenylenediamine poisoning due to black henna
}

\author{
Güntülü Şık, Agop Çıtak \\ Pediatric Intensive Care Unit, Department of Pediatrics, Istanbul University Faculty of Medicine, Istanbul, Turkey. \\ E-mail: agopcitak@hotmail.com \\ Received: 13 August 2015, Revised: 7 January 2016, Accepted: 23 March 2016
}

\begin{abstract}
SUMMARY: Şık G, Çıtak A. Fatal paraphenylenediamine poisoning due to black henna. Turk J Pediatr 2016; 58: 301-304.

Paraphenylenediamine (PPD) is an oxidative chemical allergen that can cause hypersensitivity reactions. PPD intoxication could cause severe systemic adverse effects like acute renal failure, rhabdomyolysis and multiple organ failure. In this text we present a 9 year-old female patient who developed multiple organ failure and cardiac arrhythmia as a result of extensive application of PPD added to henna to the skin. Plasma exchange (PE) and continuous venovenous hemodiafiltration (CVVHDF) were started. The patient died on day 4 after developing ventricular fibrillation that was resistant to antiarrhythmic treatment and defibrillation. In summary, the most commonly seen clinical signs in PPD intoxication are cervical, upper respiratory and muscle edema, intravascular hemolysis, rhabdomyolysis, severe cardiac arrhythmias and acute renal failure. These symptoms would be suggestive of PPD poisoning.
\end{abstract}

Key words: paraphenylenediamine, henna, plasma exchange, hemodiafiltration, pediatric intensive care.

Paraphenylenediamine (PPD), a derivative of para-nitroanilin, is a kind of aromatic amine that is widely used in several industrial products. PPD added to henna (black henna) which is often used in temporary tattoos and hair dye contains additives that increase its effectiveness. Paraphenylenediamine (PPD) ${ }^{1,2}$ is an oxidative chemical that can cause hypersensitivity reactions and systemic side effects of poisoning.

Systemic toxicity from the ingestion of PPD, either intentional or accidental, is frequently reported in India and North Africa but is less common in the developed world. Systemic intoxication commonly presents as angioedema, rhabdomyolysis, acute renal failure, hemolysis and fatal arrhythmia secondary to cardiotoxicity, with high rates of mortality ${ }^{3-6}$.

We present herein a case of systemic poisoning with PPD added to henna that lead to multiple organ failure, cardiac arrhythmia and rhabdomyolysis.

\section{Case Report}

A 9-year-old female patient presented at state hospital with complaints of feeling unwell, impaired consciousness and vomiting, which started 1 hour after black henna and hair dye was applied extensively to her skin and hair. The patient had been diagnosed as having psoriasis 3 years previously. The patient's family applied the black henna to the patient after searching the internet for alternative treatment options, believing henna to have healing properties. The complaints started 1 hour after application and the patient presented at our hospital.

The patient had a poor general condition, impaired consciousness and was assigned a Glasgow coma score (GKS) of 8. Breathing was slow and inefficient so the patient was intubated. The patient's heart rate (HR) was $80 / \mathrm{min}$, blood pressure was $72 / 33 \mathrm{mmHg}$ and pulses were weak. In the abdominal examination, the liver was palpated $3 \mathrm{~cm}$ below the costal margin. The skin was edematous, covered in erythematous plaques and gave off a pervasive odor. The color of skin was yellow-brown due to the applied substance (Figures 1).

Clinical test showed, leukocytes $34,500 / \mathrm{mm}^{3}$, AST 8,755 U/L, ALT 4,557 U/L, INR 4.3, urea $40 \mathrm{mg} / \mathrm{dl}$, creatinine $1.13 \mathrm{mg} / \mathrm{dl}$, phosphorus 
$7.5 \mathrm{mg} / \mathrm{dl}$, calcium $6.9 \mathrm{mg} / \mathrm{dl}$, CPK 2,141 U/L, blood glucose $24 \mathrm{mg} / \mathrm{dl}$, total bilirubin $8.63 \mathrm{mg} /$ $\mathrm{dl}$, direct bilirubin $2.36 \mathrm{mg} / \mathrm{dl}$, blood ammonia $198 \mathrm{mmol} / \mathrm{L}$. Blood gas test showed a $\mathrm{pH}$ of 7.14, PCO2 $36 \mathrm{mmHg}$, HCO3 $14 \mathrm{mmol} / \mathrm{L}, \mathrm{BE}$ of $-11 \mathrm{mmol} / \mathrm{L}$, lactate $15 \mathrm{mmol} / \mathrm{L}$. Blood pressure was $72 / 33 \mathrm{mmHg}$; vasopressor perfusion was initiated. The patient had a massive upper gastrointestinal hemorrhage with an INR of 4.3 despite the vitamin $\mathrm{K}$, fresh frozen plasma and ranitidine treatment. Calcium gluconate was used to treat hypocalcemia. Plasma exchange (PE) was initiated due to bleeding diathesis and liver failure. Due to the patient's somnolence, cranial computerized tomography (CT) was performed. Diffuse cerebral edema and intracranial hemorrhage in the right parietal lobe were detected. Antiedema treatment was initiated after the results showed cerebral edema.

The patient was oliguric $(<0.5 \mathrm{ml} / \mathrm{kg} / \mathrm{hr})$; urine was coffee-colored. Due to oliguria, acute renal failure, metabolic acidosis and high lactate, CVVHDF was started. She was treated with CVVHDF on the Gambro Prismaflex continuous renal replacement therapy (CRRT) machine using the AN69 filter (blood flow rate $120 \mathrm{ml} / \mathrm{min}$, dialysate flow $40 \mathrm{ml} / \mathrm{kg} / \mathrm{h}$, predilution rate $20 \mathrm{ml} / \mathrm{kg} / \mathrm{h}$, postdilution rate $20 \mathrm{ml} / \mathrm{kg} / \mathrm{h}$ ). Abdominal distention developed on day 2 after admission and abdominal CT showed free fluid collection in the perihepatic and perisplenic recesses, fatty liver, and inflammation and edema of the cutaneous and subcutaneous tissues. Plasma exchange and hemodiafiltration were continued. AST was $6,880 \mathrm{U} / \mathrm{L}$, ALT 3,613 U/L, urea $30 \mathrm{mg} /$ dl, creatinine $0.87 \mathrm{mg} / \mathrm{dl}$, INR 2.99 (Table I). On day 3 after admission, hypotension persisted despite increasing vasopressor doses. Plasma exchange and hemodiafiltration were continued. The patient died on day 4 after developing ventricular fibrillation that was resistant to antiarrhythmic treatment and defibrillation.

\section{Discussion}

The natural henna used in temporary tattoos is red in color and does not leave behind a lasting stain. It is harmless, with a low risk of allergic reaction ${ }^{7}$. Black henna dries faster, causing darker and more lasting staining. For this reason, it is frequently used in the production of hair and textile dyes and plastic bags. The most common additive contained in black henna is paraphenylenediamine (PPD), an oxidative chemical allergen that can cause hypersensitivity reactions ${ }^{1}$. The most common of such reactions are edema, erythema, erythema multiformelike skin lesions, bullous lesions, allergic contact dermatitis, eczema and permanent hypopigmentation. The reaction is generally limited to the area of application and can sometimes leave permanent scarring8,9. The skin of our patient was covered with erythemic plaques and was yellow-brown in color.

Table I. Laboratory evaluation

\begin{tabular}{lccc}
\hline & Day 1 & Day 2 & Day 3 \\
& PE+CVVHDF+FFP & PE+CVVHDF+FFP & PE+CVVHDF+FFP \\
\hline WBC (/mm3) & 34,500 & 21,200 & 14,600 \\
AST (U/L) & 8,755 & 6,880 & 4,216 \\
ALT (U/L) & 4,557 & 3,613 & 1,963 \\
INR & 4.3 & 2.9 & 1.98 \\
PT (sec) & 84.1 & 34.6 & 24.6 \\
aPTT (sec) & 76.4 & 51.2 & 46.2 \\
Urea $(\mathrm{mg} / \mathrm{dl})$ & 40 & 30 & 32 \\
Creatinine (mg/dl) & 1.13 & 0.87 & 0.69 \\
pH & 7.14 & 7.37 & 7.39 \\
T. bil $(\mathrm{mg} / \mathrm{dl})$ & 8.63 & 4.3 & 2.9 \\
D. bil $(\mathrm{mg} / \mathrm{dl})$ & 2.36 & 1.91 & 0.99 \\
Lactate $(\mathrm{mmol} / \mathrm{L})$ & 15 & 3.1 & 1.7 \\
\hline
\end{tabular}

CVVHDF: continuous venovenous hemodiafiltration; FFP: fresh frozen plasma; PE: plasma exchange 

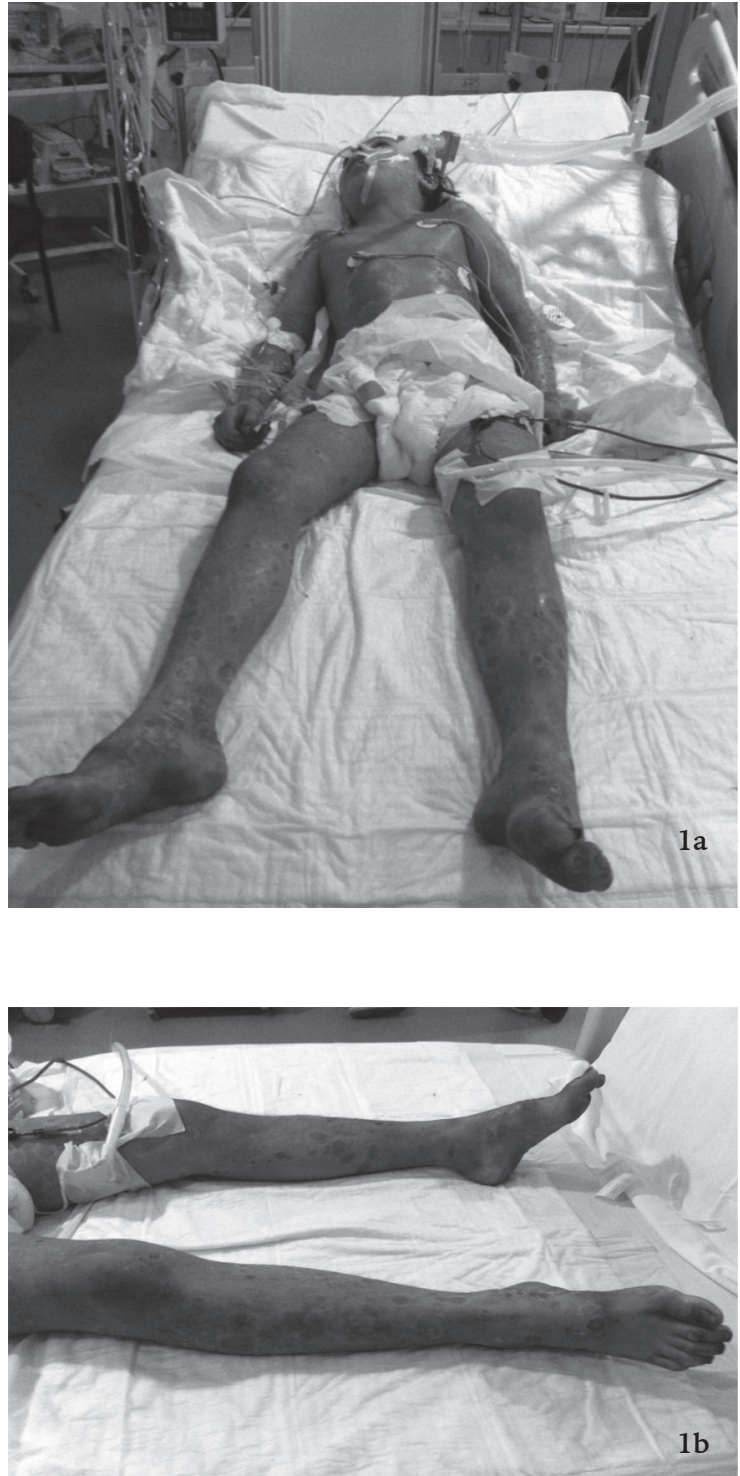

Fig. 1. a and b. The skin was edematous, covered in erythemic plaques and gave off a pervasive odor

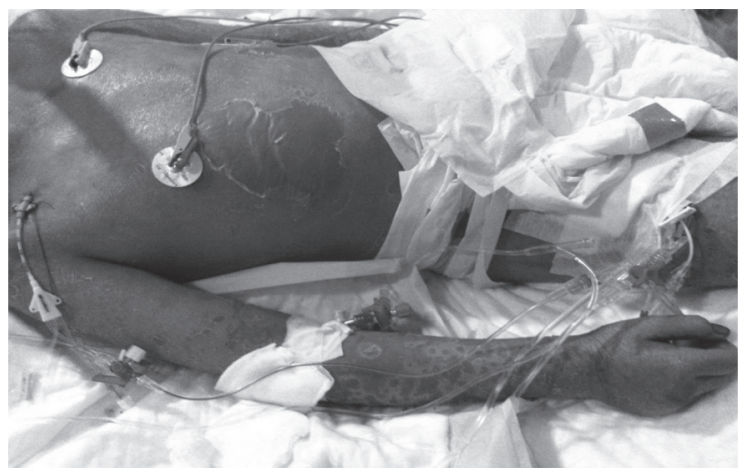

Fig. 1c. The color of skin was yellow-brown due to the applied substance
In the systemic intoxication of PPD, common symptoms are severe hypersensitivity (facial and upper respiratory edema), rhabdomyolysis and acute renal failure, cardiac complications (ventricular arrhythmia, myocarditis) and intravascular hemolysis 3,4,10. Facial and upper respiratory edema may necessitate mechanical ventilation support and tracheotomy ${ }^{11}$. Our patient exhibited intravascular hemolysis, liver failure, acute renal failure, metabolic acidosis and cardiac complications. The patient had increased need for vasopressors and died after developing severe ventricular arrhythmia.

A study from India presented 10 patients with systemic PPD intoxication following a suicide attempt. Six patients died ( $60 \%$ mortality), 2 of them from cardiac arrhythmia ${ }^{12}$. A study from Sudan described 17 patients with hair dye intoxication. Hair dye was ingested in 13 cases as a suicide attempt and in 1 by accident, while 2 patients were victims of attempted murder. Tracheotomy was performed in 8 cases, out of 12 patients that developed acute renal failure. A study from Tunisia described 19 patients that had presented at a hospital with systemic PPD intoxication. The most commonly seen symptoms were cervicofacial edema, coffee-colored urine, upper respiratory edema, oliguria, muscle edema and shock. All patients developed rhabdomyolysis and metabolic acidosis, and some had acute renal failure and hyperpotassemia ${ }^{11}$. Six patients died $(31.6 \%), 5$ of them from acute renal failure.

The most common cause of PPD intoxication is suicide ${ }^{13}$. In the majority of cases, PPD is ingested orally. In our case, application of PPD added henna to the skin was intended as a treatment for psoriasis. We observed all the clinical and laboratory findings associated with systemic PPD intoxication. The patient also had skin lesions that resembled a hypersensitivity reaction. Causes of mortality may vary, the most common ones being acute renal failure and ventricular arrhythmia. Renal replacement therapy is often administered but similar to our case, it only provides supportive treatment for acute renal and liver failure. Mortality is high in patients who develop treatment-resistant ventricular arrhythmia, which was the cause of death in our patient.

In these patients ECMO can be life saving. Intoxication, multiple organ failure, in the 
treatment of refractory heart failure and arrhythmia cases have been successfully implemented. However, due to intracranial hemorrhage and severe coagulapathy, we did not practice ECMO support with this patient.

In conclusion, PPD can be absorbed from the skin and could cause more serious complications. The most commonly seen clinical signs in PPD intoxication are cervical, upper respiratory and muscle edema, intravascular hemolysis, rhabdomyolysis, sever cardiac arrhythmias and acute renal failure. There is no specific antidote to PPD and treatment is primarily conservative. The mortality rate is very high even after early intervention $(31 \%)^{14}$. We conclude that the characteristic angioedema of the face and neck with difficulty in breathing, impaired consciousness and vomiting, acute renal failure manifesting as chocolate browncolored urine, intravascular hemolysis and severe cardiac arrhythmias could be suggestive of PPD poisoning.

\section{REFERENCES}

1. Kang IJ, Lee MH. Quantification of paraphenylenediamine and heavy metals in henna dye. Contact Dermatitis 2006; 55: 26-29.

2. Martin JA, Hughes TM, Stone NM. 'Black Henna' tattoos: an occult source of natural rubber latex allergy. Contact Dermatitis 2005; 52: 145-146.

3. Jayachandran K, Saravanan T, Thomas M. An interesting case of rhabdomyolysis with acute renal failure. J Assoc Physicians India 2003; 51: 1283.

4. Sampathkumar K, Sooraj YS, Ajeshkumar RP, et al.
Rhabdomyolysis due to hair dye poisoning: an emerging threat. Indian J Crit Care Med 2007; 11: 212-214.

5. Goldenberg A, Jacob SE. Paraphenylenediamine in black henna temporary tattoos: 12-year Food and Drug Administration data on incidence, symptoms, and outcomes. J Am Acad Dermatol. 2015; 4: 724-726.

6. Elevli M, Civilibal M, Ersoy O, Demirkol D, Gedik $\mathrm{AH}$. Paraphenylenediamine hair dye poisoning: an uncommon cause of rhabdomyolysis. Indian J Pediatr 2014;7: 709-711.

7. Neri I, Guareschi E, Savoia F, et al. Childhood allergic contact dermatitis from henna tattoo. Pediatr Dermatol 2002; 19: 503-505.

8. Le Coz CJ, Lefebvre C, Keller F, et al. Allergic contact dermatitis caused by skin painting (pseudotattooing) with black henna: a mixture of henna and p-phenylenediamine and its derivatives. Arch Dermatol 2000; 136: 1515-1517.

9. Sidwell RU, Francis ND, Basrab T, et al. Vesicular erythema multiforme-like reaction to paraphenylenediamine in a henna tattoo. Pediatr Dermatol 2008; 25: 201-204.

10. Singla S, Miglani S, Lal AK, et al. Paraphenylenediamine (PPD) poisoning. J Acad Clin Care Med 2005; 6: 236238.

11. Kallel H, Chelly H, Dammak H, et al. Clinical manifestations of systemic paraphenylenediamine intoxication. J Nephrol 2005; 18: 308-311.

12. Sachin S. Soni, Amit P. Nagarik. Systemic toxicity of paraphenylenediamine. Indian J MedSci 2009; 4: 63.

13. Abdelraheem MB, Elbushra M, Ali el-T, et al. Filicide and suicide in a family by paraphenylenediamine poisoning: a mother who committed suicide and poisoned her four children of which one died. Toxicoll and Health 2014; 30: 679-682.

14. Anuradha S, Arora S, Mehrotra S, et al. Acute renal failure following paraphenylenediamine (PPD) poisoning: a case report and review. Ren Fail 2004; 26: 329-332. 